\title{
Primary versus recurrent surgery for glioblastoma-a prospective cohort study
}

\author{
Maja Chava Rubin ${ }^{1}$ (ID $\cdot$ Lisa Millgård Sagberg ${ }^{1,2} \cdot$ Asgeir Store Jakola ${ }^{3,4} \cdot$ Ole Solheim ${ }^{1,2}$
}

Received: 9 July 2020 / Accepted: 2 October 2020 / Published online: 14 October 2020

(C) The Author(s) 2020

\begin{abstract}
Background There is currently limited evidence for surgery in recurrent glioblastoma (GBM). Our aim was to compare primary and recurrent surgeries, regarding changes in perioperative, generic health-related quality of life (HRQoL), complications, extents of resection and survival.

Methods Between 2007 and 2018, 65 recurrent and 160 primary GBM resections were prospectively enrolled. HRQoL was recorded with EQ-5D 3L preoperatively and at 1 month postoperatively. Median perioperative change in HRQoL and change greater than the minimal clinically important difference (MCID) were assessed. Tumour volume and extent of resection were obtained from pre- and postoperative MRI scans. Survival was assessed from date of surgery.

Results Comparing recurrent surgeries and primary resections, most variables were balanced at baseline, but median age ( 59 vs. $62, p=0.005)$ and median preoperative tumour volume ( 14.9 vs. $25.3 \mathrm{ml}, p=0.001)$ were lower in recurrent surgeries. There were no statistically significant differences regarding complication rates, neurological deficits, extents of resection or EQ-5D 3L index values at baseline and at follow-up. Twenty (36.4\%) recurrent resections vs. 39 (27.5\%) primary resections reported clinically significant deterioration in HRQoL at follow-up. Stratified by clinically significant change in EQ-5D 3L, the survival distributions were not statistically significantly different in either group. Survival was associated with extent of resection $(p=$ 0.015) in recurrent surgeries only.

Conclusions Outcomes after primary and recurrent surgeries were quite similar in our practice. As surgery may prolong life in patients where gross total resection is obtainable with reasonable risk, the indication for surgery in GBM should perhaps not differ that much in primary and recurrent resections.
\end{abstract}

Keywords Glioblastoma $\cdot$ Neurosurgery $\cdot$ Patient-reported outcome measures $\cdot$ Quality of life

This article is part of the Topical Collection on Brain Tumors

Presentation at a conference: Some of the results have been presented as a free oral presentation at the Annual Meeting of the Norwegian Neurosurgical Association, October 2019, Oslo, Norway.

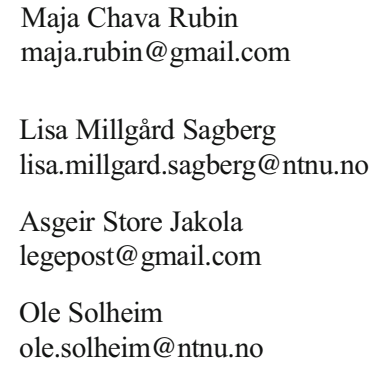

1 Department of Neuromedicine and Movement Science, Faculty of Medicine and Health Sciences, NTNU, Norwegian University of Science and Technology, Trondheim N-7491, Norway

2 Department of Neurosurgery, St. Olav’s University Hospital, Trondheim, Norway

3 Department of Neurosurgery, Sahlgrenska University Hospital, Gothenburg, Sweden

4 Institute of Neuroscience and Physiology, Sahlgrenska Academy, Gothenburg, Sweden 


$\begin{array}{ll}\text { Abbreviations and acronyms } \\ \text { CCI } & \text { Charlson comorbidity index } \\ \text { CI } & \text { Confidence interval } \\ \text { CT } & \text { Computer tomography } \\ \text { FLAIR } & \text { Fluid-attenuated inversion recovery } \\ \text { GBM } & \text { Glioblastoma } \\ \text { HRQoL } & \text { Health-related quality of life } \\ \text { KPS } & \text { Karnofsky performance status } \\ \text { MCID } & \text { Minimal clinically important difference } \\ \text { MRI } & \text { Magnetic resonance imaging } \\ \text { WHO } & \text { World Health Organization }\end{array}$

\section{Introduction}

Glioblastoma (GBM) is the most common primary malignant brain tumour in adults [24]. Newly diagnosed GBM is usually treated with so-called maximal safe surgical resection if feasible, followed by adjuvant radiation and concomitant and often adjuvant chemotherapy [34]. Despite multimodal treatment, relapse is inevitable, and the prognosis remains poor. However, due to the lack of evidence, there is no consensus on the best way to treat recurrent GBM. It is so far not settled whether reoperations for GBM prolong survival [9, 40]. Neither is the literature conclusive concerning the potential dose-response relationship of extent of resection on survival after recurrence $[2,6,18,23,25,26,28,29,32,35,37,39]$. Hence, some hospitals never offer resections at recurrence, although others do.

Some studies report increased rates of surgery-related morbidity and complications in recurrent disease [6,21,29], and potential survival benefit should be balanced against other clinical outcomes [20]. While several studies mention health-related quality of life (HRQoL) as an essential aspect in this palliative setting, patient-reported perioperative HRQoL is barely studied in this context [3, 9, 10, 17, 27, 36].

In the present prospective cohort study, we sought to compare treatment results after primary versus recurrent surgeries for GBM, in terms of changes in perioperative and generic HRQoL, complication rates, extents of surgical resection and survival.

\section{Material and methods}

\section{Study population}

The project is based on prospectively collected data from patients $\geq 18$ years of age, undergoing surgery for GBMs at St. Olavs University Hospital, Norway, from September 2007 through August 2018. Patients eligible for enrolment were patients considered suited for surgery based on local treatment indications. Patients were included after informed consent. At
St. Olavs Hospital, recurrent surgery is often considered (although with exemptions) an option for patients who are functionally independent (e.g. Karnofsky performance status (KPS) $\geq 70$ ), enhancing tumour volumes believed available for gross total resection, and when recurrence takes place at least six months after primary resections. The histopathological diagnosis of GBM was graded and confirmed by a neuropathologist, according to the World Health Organization (WHO) classification at time of diagnosis [13, 16]. Patients with histopathological anaplastic astrocytoma and evidence of necrosis on magnetic resonance imaging (MRI) were also included, as they are shown to have the same prognosis as patients with histopathological grade IV astrocytoma [15] and were treated as GBMs at our hospital. Patients with prior histopathological diagnosis of glioma grade I-III without evidence of necrosis on MRI, who transformed to GBM at a later stage, were not included. Multifocal tumours operated in more than one session were assessed as single operations. There were 65 recurrent surgeries included in the study, 19 of which were conducted on eight patients. Twenty-eight patients underwent both primary and recurrent resections and were included in both groups. The inclusion process is shown in the flowchart labelled Fig. 1. Amongst the 23 patients still alive at the end of follow-up, the median (range) duration of follow-up was 23 months (10-96).

\section{Collection of data}

A HRQoL-questionnaire was completed one to three days preoperatively by self-administration or with assistance from next of kin or a nurse, and at one month postoperatively in a structured telephone interview conducted by a research nurse. KPS was scored by the operating surgeon just prior to surgery and by a research nurse in a structured phone interview one month postoperatively. KPS was missing in 10 patients and was therefore assessed retrospectively from electronic medical records and dichotomized to above and below 70 . Charlson Comorbidity Index (CCI) [4], postoperative complications within 30 days postoperatively classified with the Landriel classification [14] and new or worsened neurological deficits at the time of discharge were collected retrospectively from electronic medical records from the university hospital and the seven local hospitals in the catchment region.

Tumour volume data was obtained from pre- and early postoperative MRI scans (taken within $72 \mathrm{~h}$ of surgery) and calculated with the ellipsoid formula $\left(\left(4 \pi r_{1} \cdot r_{2} \cdot r_{3}\right) / 3\right.$, where $r_{x}$ was defined as diameter/2 from the largest perpendicular diameters in perpendicular image dimensions). In 28 selected cases with oddly shaped tumours, volume data was obtained by semi-automatic tumour segmentation (3D slicer). Only contrast-enhancing tumour tissue and tissue within the enhancement rim was included when calculating the pre- and postoperative volumes. For recurrent tumours, tumour cavities 
Fig. 1 Flow chart showing the inclusion process

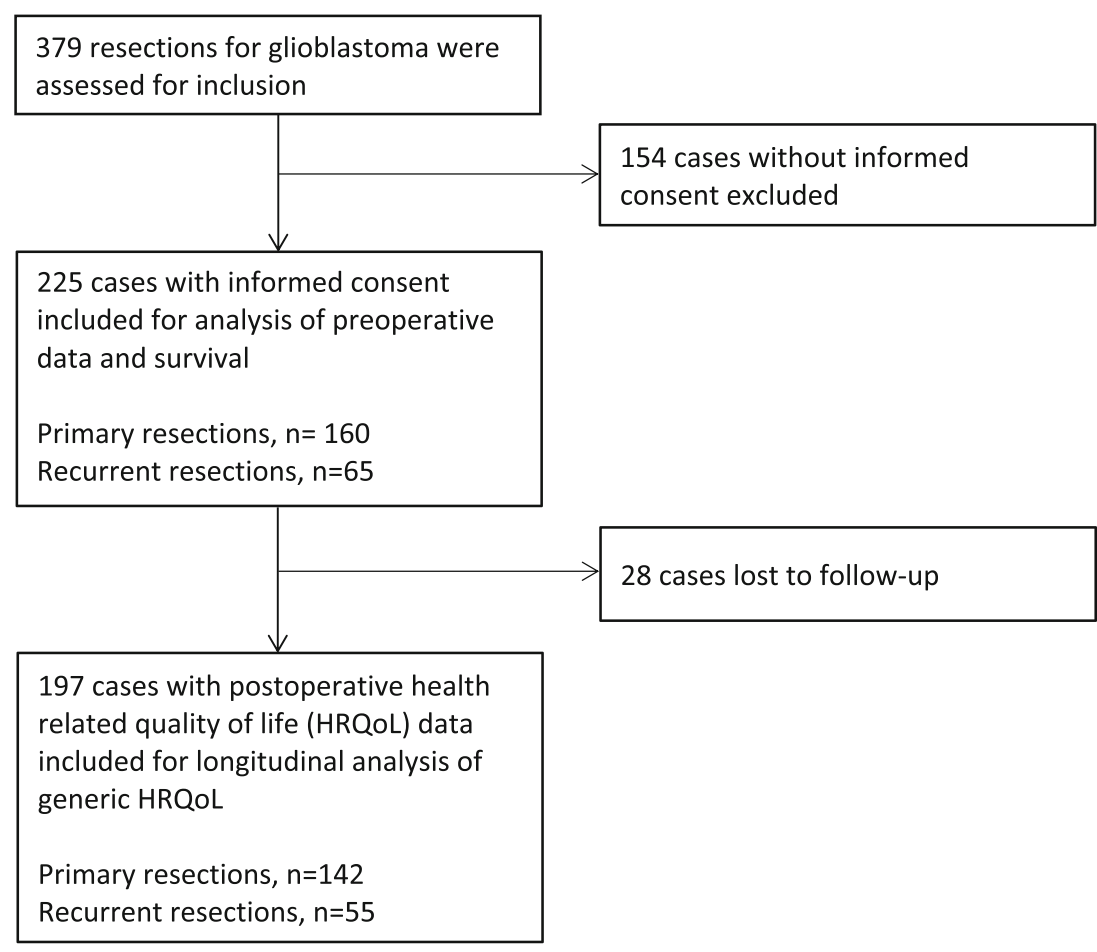

were subtracted from the tumour volume if there was a clear fluid signal on fluid-attenuated inversion recovery (FLAIR) images. In three patients, MRI images were not available, and computed tomography (CT) images were used in tumour volume assessments. The extent of resection was classified as either gross total $(100 \%)$, near total $(90-99 \%)$ or subtotal resection $(<90 \%)$. Eloquence was graded as suggested by Sawaya et al. [31], but we chose to grade hippocampal tumours as eloquent as well. For multifocal tumours, the most eloquent part of the tumour was scored.

\section{HRQoL instrument}

HRQoL was assessed with the generic EQ-5D 3L questionnaire, developed by the EuroQol Group [38]. In this questionnaire, HRQoL is scored in five single-item dimensions: Mobility, Self-Care, Usual Activities, Pain/Discomfort and Anxiety/Depression. The subitem scores can be converted to a global health index value. This EQ-5D 3L index value has a range from -0.594 to one, where one equals perfect health, zero equals death, and negative values are considered worse than death. The questionnaire is validated in the Norwegian population [22], and the EQ-5D 3L index value was recently shown to be responsive in glioma patients who deteriorate functionally after surgery [30].

\section{Ethical approval}

All patients provided written informed consent prior to inclusion. The data collection and study protocol (REC ref.
2014/103-1) was approved by the Regional Committee for Medical Research in Central Norway.

\section{Missing data}

Twenty-eight patients with missing HRQoL forms at one month were included in analyses at baseline but excluded from the longitudinal analysis. Three patients died before follow-up, and for these patients, the EQ-5D 3L index value at one month was imputed as zero, as it equals death. Furthermore, we performed a selective imputation in 13 missing subdomains $(0.06 \%$ of 2110 subdomains in total) in eleven different patients. Eleven of these subdomains were missing in preoperative data, and two at one month. Nine of these patients had filled in the disease-specific instrument EORTC QLQ-C30 and QLQ-BN20 [1] the same day as filling in EQ-5D 3L, and for these patients, we imputed a level of subdomain of EQ-5D $3 \mathrm{~L}$ equal to the answers given in the EORTC QLQ-C30 and QLQ-BN20. In the two remaining patients, we imputed the median score from their four other subdomains of EQ-5D 3L.

\section{Statistical analysis}

Statistical analyses were performed using SPSS version 25.0 (IBM Corporation, Armonk, New York). Statistical level of significance was set to $p<0.05$. All tests were two-sided. Normal distribution of data was assessed with Q-Q-plots and the Shapiro-Wilk test. Central tendencies are presented as median and range for skewed continuous data. Comparisons between recurrent surgeries and primary resections for 
continuous skewed data were performed with the MannWhitney $U$ test. Pearson's chi square test or Fisher's exact test was used for nominal and ordinal variables in contingency tables.

The EQ-5D index value was calculated according to the EuroQol scoring manual, using an empirically derived set of calculations [7]. We assessed change in EQ-5D index value from baseline to one month postoperatively by dividing it into the three categories, "improved", "unchanged" and "deteriorated", defined as a change greater than the minimal clinical important difference (MCID). MCID is defined as "the smallest difference in score in the domain of interest that patients perceive as important, either beneficial or harmful, and which would lead the clinician to consider a change in the patient's management" [5] and was shown to be 0.13-0.15 for EQ-5D 3L index value in glioma patients undergoing surgery [30]. In the present study, MCID in EQ-5D 3L index value was defined as $\geq 0.15$.

Possible predictors of clinically significant postoperative deteriorations $(\geq 0.15$ negative change in EQ-5D 3L index value) at one month with $p<0.1$ in univariable analyses were planned to be tested for independent significance $(p<0.05)$ in a multivariable model. The following variables were screened for trends $(p<0.1)$ in univariable analyses for possible inclusion in multivariable analyses: age $(\mathrm{y} / \mathrm{n})$, preoperative KPS $\geq$ $70(\mathrm{y} / \mathrm{n}), C C I \geq 2(\mathrm{y} / \mathrm{n})$, preoperative tumour volume $(\mathrm{ml})$, eloquent tumour location $(\mathrm{y} / \mathrm{n})$, gross total resection $(\mathrm{y} / \mathrm{n})$, postoperative motor or language deficits $(\mathrm{y} / \mathrm{n})$ and moderate/ severe complications (defined as Landriel grade $\geq 2)(\mathrm{y} / \mathrm{n})$.

The presence of a ceiling effect for EQ-5D 3L index values was assessed by describing the proportion of patients with the highest achievable index value. As suggested by McHorney et al. [19], the ceiling effect was considered small if $\leq 15 \%$ of the patients achieved an index value of 1.0 (maximum score) and moderate if $>15 \%$.

Survival was assessed from date of surgery (either primary or recurrent surgeries) and stratified based on clinically significant change in EQ-5D 3L index value (improvement, unchanged and deterioration), as well as extent of surgical resection (complete radiological resection, near-total extent of resection and subtotal extent of resection). Survival analyses are presented as Kaplan-Meier plots and compared with log-rank tests. In the recurrent surgery group, 11 cases with multiple reoperations were excluded from the survival analysis, in order to not count each patient more than once.

\section{Results}

\section{Patient characteristics at baseline}

Baseline characteristics for preoperative data in 225 included cases are summarized in Table 1. As seen, most variables at baseline were quite balanced between recurrent surgeries and primary resections, including sex, comorbidity, neurological functional level and tumour eloquence. However, median age at surgery was significantly lower in the recurrent surgeries (59 vs. $62, p=0.005$ ), and median preoperative tumour volume was lower (14.9 vs. $25.3 \mathrm{ml}, p=0.001)$. Furthermore, patients undergoing recurrent resections had significantly less preoperative headache, motor deficits and cognitive deficits than patients undergoing primary surgery.

\section{Treatment results}

EQ-5D 3L index values preoperatively and at one month follow up are presented in Table 2. As seen, there was no significant difference in EQ-5D 3L index values at baseline, nor at one month follow-up in the two groups. The median EQ-5D $3 \mathrm{~L}$ index value in the recurrent surgery group was 0.796 $(0.040-1.00)$ preoperatively and $0.760(-0.170$ to 1.00$)$ postoperatively and $0.760(-0.480$ to 1.00$)$ and 0.796 $(-0.240$ to 1.00$)$, respectively, in the primary resection group. However, the median perioperative change in EQ-5D 3L index value was significantly lower for reoperations, compared with primary resections $(-0.037$ vs. $0.00, p=0.04)$. Furthermore, there was no statistically significant difference regarding complication rates, new/worsened neurological deficits, nor extent of surgical resection comparing recurrent surgeries and primary resections.

Table 2 shows that amidst the 55 recurrent surgeries, 20 $(36.4 \%)$ reported clinically significant deterioration in HRQoL at one month, compared with 39 (27.5\%) in the primary resection group. Clinically significant improvement was seen in nine cases $(16.4 \%)$ vs. 38 cases $(26.8 \%)$. In terms of clinically significant change in HRQoL following surgery, there was no statistically significant difference between the two groups. We were not able to identify predictors of clinically significant postoperative deterioration in EQ-5D 3L index value in the reoperation group, as none of the listed variables showed statistical trends $(p<0.1)$ in univariable analyses.

The highest achievable EQ-5D 3L index value preoperatively was seen in $14(25.5 \%)$ recurrent resections and 38 $(26.8 \%)$ primary resections, resulting in a ceiling effect considered as moderate $(>15 \%)$. All analyses were also repeated on data where patients in the recurrent resection group were only included once (first recurrent resection), but this did not alter the results in any significant way (data not shown).

\section{Survival analysis}

At the time of analysis, 23 patients were still alive, 22 of them having undergone primary resections only. Counted from the date of surgery (being primary or recurrent operations), median survival in months $(95 \% \mathrm{CI})$ was $14.5(12.6-16.3)$ and 8.5 
Table 1 Patient characteristics at baseline

\begin{tabular}{|c|c|c|c|}
\hline Variable & $\begin{array}{l}\text { Recurrent surgeries } \\
(n=65)\end{array}$ & $\begin{array}{l}\text { Primary resections } \\
(n=160)\end{array}$ & $\begin{array}{l}p \\
\text { value }\end{array}$ \\
\hline Age, median (range) & $59(28-78)$ & $62(29-81)$ & 0.005 \\
\hline Gender, $n(\%)$ & & & 0.764 \\
\hline Female & $27(41.5)$ & $62(38.8)$ & \\
\hline Male & $38(58.5)$ & $98(61.3)$ & \\
\hline Charlson Comorbidity Index $\geq 2, n(\%)$ & $3(4.6)$ & $13(8.1)$ & 0.567 \\
\hline Karnofsky performance status, $n(\%)$ & & & 0.845 \\
\hline$\geq 70$ & $55(84.6)$ & $132(82.5)$ & \\
\hline$<70$ & $10(15.4)$ & $28(17.5)$ & \\
\hline \multicolumn{4}{|l|}{ Preoperative symptoms, $n(\%)$} \\
\hline Headache & $8(12.3)$ & $63(39.4)$ & $<0.001$ \\
\hline Motor deficits & $10(15.4)$ & $50(31.3)$ & 0.019 \\
\hline Cognitive deficits & $18(27.7)$ & $69(43.1)$ & 0.035 \\
\hline Seizures & $17(26.2)$ & $50(31.3)$ & 0.521 \\
\hline $\begin{array}{l}\text { Preoperative tumour volume in ml, median } \\
\text { (range) }\end{array}$ & $14.91(0.98-101.18)$ & $25.33(1.34-143.15)$ & 0.001 \\
\hline Tumour eloquence (Sawaya), $n(\%)$ & & & 0.982 \\
\hline Not eloquent & $18(27.7)$ & $46(28.7)$ & \\
\hline Near eloquent & $17(26.2)$ & $40(25.0)$ & \\
\hline Eloquent & $30(46.2)$ & $74(46.3)$ & \\
\hline $\begin{array}{l}\text { Time since primary resection in months, } \\
\text { median (range) }\end{array}$ & $15.8(5.5-108.1)$ & $\mathrm{N} / \mathrm{A}$ & $\mathrm{N} / \mathrm{A}$ \\
\hline Recurrence diagnosed due to, $n(\%)$ & & N/A & N/A \\
\hline New/worsened symptoms & $17(26.2)$ & & \\
\hline Routine imaging & $48(73.8)$ & & \\
\hline
\end{tabular}

(7.2-9.9), log-rank $p<0.001$, respectively. When stratified for clinically significant change in EQ-5D 3L, the survival distributions were not statistically significantly different in the recurrent resection group $(p=0.881)$ nor the primary resection group ( $p=0.801)$. Figure 2 shows Kaplan-Meier curves for survival in relation to perioperative change in HRQoL for primary and recurrent resections separately. Survival after recurrent surgery was associated with extent of resection ( $p=$ 0.015 ), as shown in Figure 3. However, in primary resections, this association was not statistically significant $(p=0.104)$.

\section{Discussion}

In this longitudinal study, we found that the risk of clinically significant perioperative deterioration in HRQoL, risk of neurological deficits, complications and extents of resection were rather comparable in primary and recurrent surgeries for GBM. About a third of the patients undergoing both primary and recurrent surgeries reported clinically significant deterioration in HRQoL one month after surgery. Median perioperative change in EQ-5D index value was slightly lower in the recurrent surgery group, but the difference is not clinically significant. We were not able to identify predictors of clinically significant deterioration in patients undergoing recurrent surgeries. Gross total resection was associated with increased survival in patients undergoing recurrent surgery. Still, median postoperative survival was about six months longer after primary surgeries compared with recurrent surgeries. Although results after surgeries for recurrent GBM will depend on case selection, risks and results may not be very different from primary resections, as observed in this cohort study from our practice. Indications for surgical resection in GBM should perhaps not necessarily be much different in primary and recurrent surgeries, as patients may benefit from resection if gross total resection is obtainable with reasonable risk.

The few previous studies that evaluate patient-reported perioperative HRQoL in recurrent GBM are characterized by small patient groups, including gliomas of lower WHO grade and focusing on other outcome measures [8, 33, 35]. Surgical indications will presumably have large effects on study findings in this setting. In the present study, patients undergoing recurrent surgeries for GBM were significantly younger and had less preoperative symptoms and smaller tumour volumes, compared with patients who underwent primary resections. This, combined with the lack of difference in EQ-5D 3L index value in primary versus recurrent resections, indicates a significant selection bias, as patients in a good 
Table 2 Treatment results

\begin{tabular}{|c|c|c|c|}
\hline Variables & Recurrent surgeries $(n=65)$ & Primary resections $(n=160)$ & $p$ value \\
\hline Postoperative complications, $n(\%)$ & & & 0.266 \\
\hline Landriel grade I & $16(24.6)$ & $39(24.4)$ & \\
\hline Landriel grade II & $9(13.8)$ & $9(5.6)$ & \\
\hline Landriel grade III & $2(3.1)$ & $4(2.5)$ & \\
\hline Landriel grade IV & $1(1.5)$ & $2(1.3)$ & \\
\hline New/worsened language or motor deficits at discharge, $n(\%)$ & $8(12.3)$ & $29(18.1)$ & 0.327 \\
\hline Extent of surgical resection, $n(\%)$ & & & 0.236 \\
\hline Gross total resection $(100 \%)$ & $24(36.9)$ & $52(32.5)$ & \\
\hline Near-total resection $(90-99 \%)$ & $28(27.7)$ & $63(39.4)$ & \\
\hline Subtotal resection $(<90 \%)$ & $23(35.4)$ & $45(28.1)$ & \\
\hline Preoperative EQ-5D index value, median (range) & $0.796(0.040-1.00)$ & $0.760(-0.480$ to 1.00$)$ & 0.167 \\
\hline Postoperative (one month) EQ-5D index value ${ }^{\mathrm{a}}$, median (range) & $0.760(-0.170$ to 1.00$)$ & $0.796(-0.240$ to 1.00$)$ & 0.352 \\
\hline Perioperative change in EQ-5D index value ${ }^{\mathrm{a}}$, median (range) & $-0.037(-0.820$ to 0.510$)$ & $0.000(-0.88$ to 1.17$)$ & 0.041 \\
\hline Perioperative change in EQ-5D index value (MCID $\geq 0.15)^{\mathrm{a}}, n(\%)$ & & & 0.235 \\
\hline Improved & $9(16.4)$ & $38(26.8)$ & \\
\hline Unchanged & $26(47.3)$ & $65(45.8)$ & \\
\hline Deteriorated & $20(36.4)$ & $39(27.5)$ & \\
\hline \multicolumn{4}{|l|}{ Survival in months ${ }^{\mathrm{b}}$, median $(95 \% \mathrm{CI})$} \\
\hline From “current" surgery & $8.5(7.2-9.9)$ & $14.5(12.6-16.3)$ & $<0.001$ \\
\hline From primary resection & $22.7(14.8-30.7)$ & $14.5(12.6-16.3)$ & \\
\hline \multicolumn{4}{|l|}{ Missing data, $n(\%)$} \\
\hline Lost to follow-up ${ }^{c}$ & $10(15.4)$ & $18(11.3)$ & 0.383 \\
\hline
\end{tabular}

a 28 cases excluded from longitudinal health-related quality of life (HRQoL) analysis due to missing HRQoL data

${ }^{\mathrm{b}} 11$ cases excluded from survival analysis in order to only count each patient once

${ }^{\mathrm{c}}$ Not including three patients dead before 1 month follow up, as they were included in HRQoL analyses

a

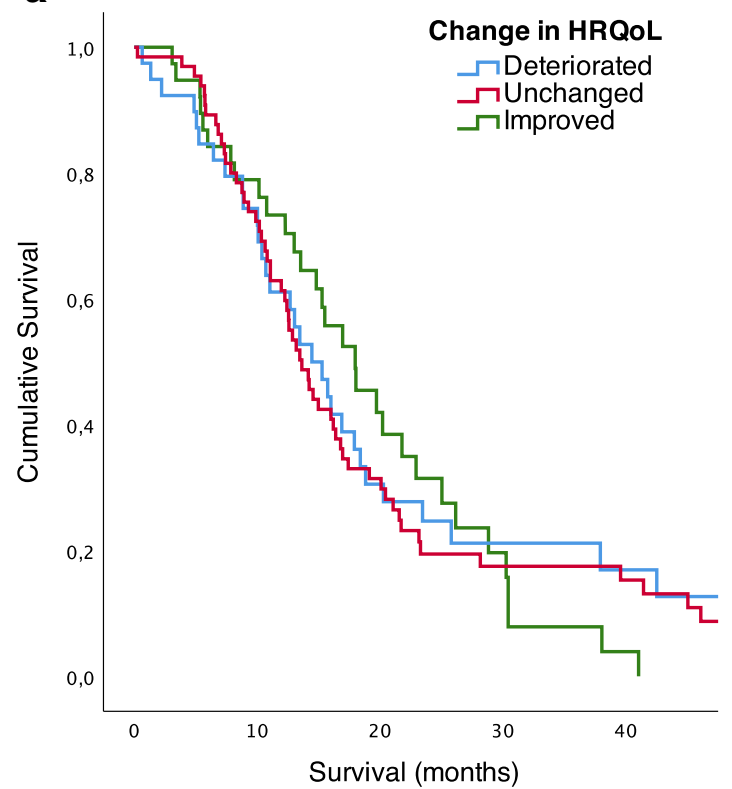

b

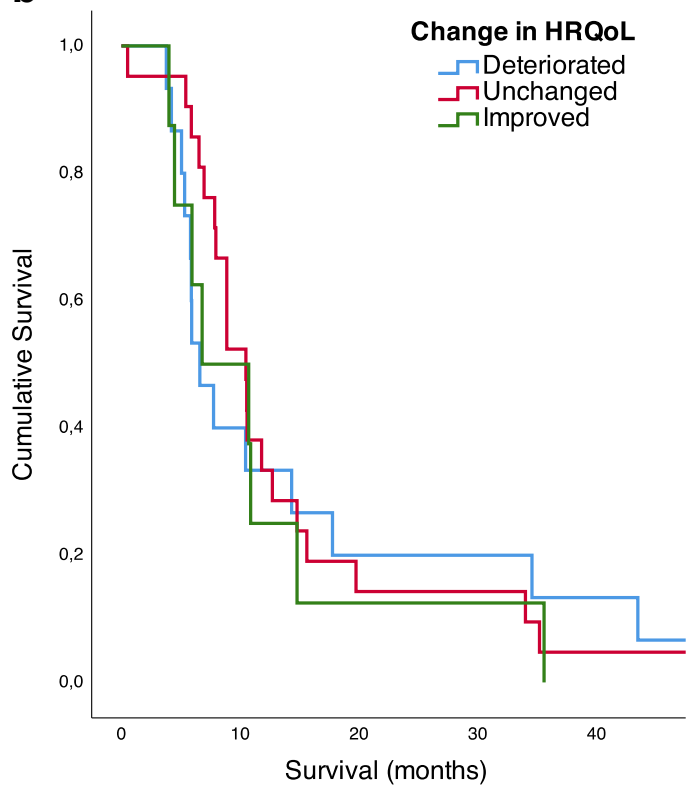

Fig. 2 Kaplan-Meier curve of survival (log-rank test) in relation to perioperative change in health-related quality of life (HRQoL), MCID $\geq 0.15$. a Primary resections $(n=142, p=0.801)$. b Reoperations $(n=44, p=0.881)$ 
a

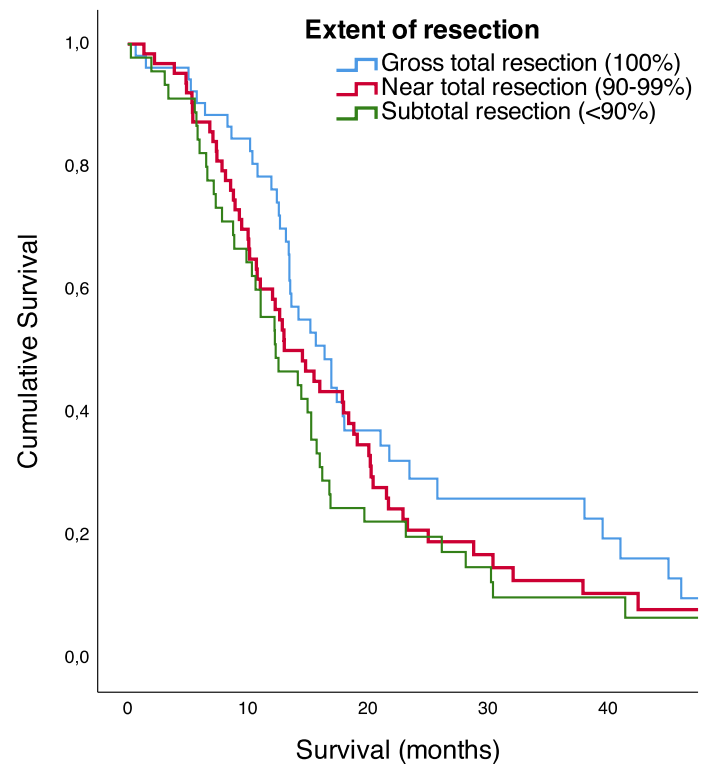

b

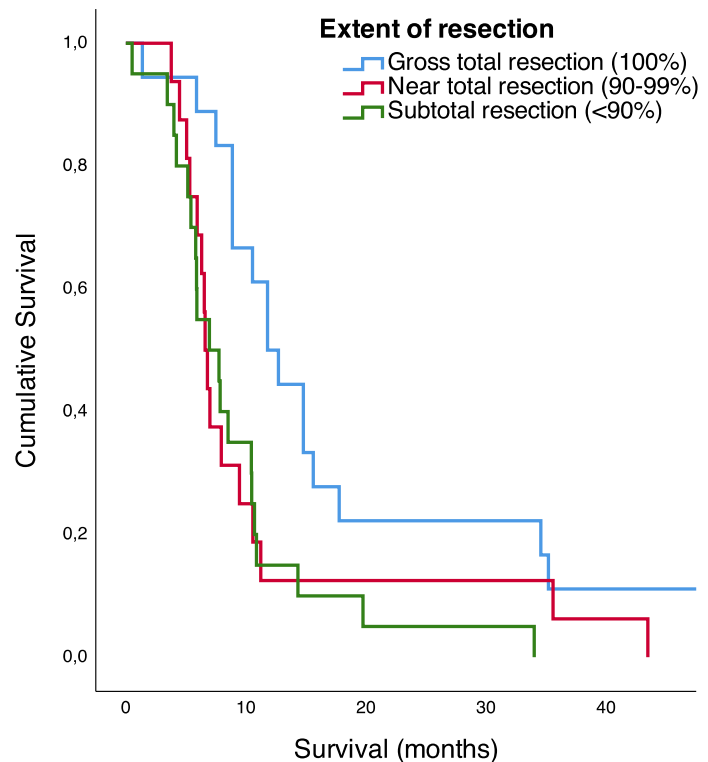

Fig. 3 Kaplan-Meier curve of survival (log-rank test) in relation to extent of resection. a Primary resections $(n=160, p=0.104)$. b Reoperations $(n=54$, $p=0.015$ )

preoperative state are more likely to be offered repeated resections. However, the stable EQ-5D 3L index value may also in part be explained by a possible response shift, as people tend to adapt to their situation over time, thereby changing their perceived HRQoL [12]. Furthermore, a majority of the recurrent operations in this study were done in patients diagnosed with asymptomatic progression at routine follow-ups. This reduces the potential for improvement of symptoms and thereby likely also the potential of HRQoL improvement. Due to the smaller median tumour volumes in the reoperation group, the potential for symptom relief caused by reducing mass effect may also be smaller in recurrent resections.

In concordance with several studies, we found a possible survival benefit in reoperations achieving gross total resection, compared with a lesser degree of resection $[2,18,23,25,28$, $29,32,35,39]$. The effect of gross total resection at recurrence may be even larger than for primary resections. This may be explained by the fact that other treatment options are often few and less likely to have significant benefits at the time of recurrence. However, since most of these studies are neither randomized, controlled nor prospective, differentiating the effect of resection on survival from selection bias is difficult, as it leaves the possibility that the tumours that are available for gross total resection merely attain a better prognosis. Oppenlander et al. reported that maximizing the extent of resections also increases the risk of complications following surgery [23], and some studies show an increased rate of complications in reoperations compared with primary resections $[6$, 21, 29]. Nevertheless, in the present study, we found similar rates for complications and new neurological deficits in primary and recurrent resections. Furthermore, two recently published articles problematize the lacking use of time-dependent analysis in survival analyses, and both conclude that when treating reoperation as a time-dependent covariate, reoperation in general does not seem to prolong the overall survival $[9,40]$. Hopefully, a much-needed randomized multicenter trial on reoperation of GBM, which is currently recruiting (NCT 02394626), will give us some answers on this regard.

Median postoperative survival was only 8.5 months following surgery for recurrent disease. When exploring survival in light of clinically significant patient-reported perioperative change in HRQoL, we found that there was no significant difference in survival for the three groups (improvement, unchanged, deterioration), suggesting that perioperative change in HRQoL may have a limited impact on survival. Still, we have earlier found that early postoperative deterioration in HRQoL may be associated with shorter survival in GBM patients [11].

Even though more than a third of the reoperated patients reported a clinically significant deterioration in HRQoL one month after surgery, we failed to identify predictors of this deterioration. Deterioration may not necessarily be entirely treatment related but could be related to the disease progression or the emotional distress of living with an incurable disease. Since treatment is essentially palliative, potential survival benefits should be evaluated in light of the effect reoperations have on HRQoL. Should a possible marginal increase in survival supersede the risk of deterioration in overall HRQoL in the patients remaining life span? This question remains to be considered before making treatment decisions in individual patients. The chance of obtaining a safe gross total resection and therefore a potential survival benefit should possibly be given much weight in the lack of predictors for worsening of HRQoL. 
Strengths of this study include a longitudinal design with prospectively collected HRQoL data and the use of MCID defining clinically significant postoperative changes in patient-reported HRQoL. The multifaceted EQ-5D 3L questionnaire used for collection of HRQoL data was chosen due to its simple and generic nature to improve compliance. There are also some limitations. Generally, results following both primary and recurrent surgeries for GBM will depend much on treatment indications and the surgical decisions that are made, especially when evaluating parameters like survival. The selective imputation we performed might also have contributed to this selection bias. Furthermore, possible adjuvant therapy was not taken into account in the analyses. Adjuvant treatment after recurrent surgeries is highly individualized based on previous treatment responses, molecular markers (MGMT status), previous treatment, time since first-line treatment, postoperative results after recurrence operations etc. Adjuvant therapy like second-line chemotherapy, reradiation and/or gamma knife radiosurgery might have had an impact on survival for some of the patients. We therefore cannot exclude that possible adjuvant therapy influenced outcome, neither can we rule out that this might appear as a causality because patients with prolonged survival live long enough to receive more adjuvant therapy. Another major limitation is the relatively small sample size, though exceeding other studies on the same subject. The moderate ceiling effect of the EQ-5D index value might have led to a reduced responsiveness for improvement in our study, since patients in a good preoperative condition could only stay unchanged or worsen. We chose to use patients undergoing primary surgery for GBM as a reference, in order to enhance interpretation of results. This comparison may be affected by the aforementioned selection bias as well as a possible response shift from HRQoL state at primary resection to state at re-resection [12]. Additionally, focusing on operations and not individual patients, some patients are counted more than once, either as having undergone both primary and recurrent resections or multiple resections in the study period.

\section{Conclusions}

In this prospective cohort study comparing primary and recurrent surgeries for GBM, pre- and postoperative global HRQoL, the risk of neurological deficits, complication rates and extents of resection were rather comparable. In both groups, about a third reported clinically significant deterioration and almost half of the patients reported unchanged HRQoL perioperatively. Gross total resection was associated with increased survival in patients undergoing recurrent surgery. As surgery may prolong life in patients where gross total resection is obtainable with reasonable risk, the indication for surgical resection in GBM should perhaps not differ that much in primary and recurrent surgeries.

Acknowledgements We would like to thank Camilla Brattbakk and Linda Mohrsen Nordtvedt for assisting in the collection of data.

Author contributions All the authors contributed to the study conception, design and data collection. Material preparation and analysis were performed by Maja Chava Rubin and Ole Solheim. The first draft of the manuscript was written by Maja Chava Rubin, and all the authors commented on previous versions of the manuscript. All the authors read and approved the final version of the submitted manuscript.

Funding Open access funding provided by NTNU Norwegian University of Science and Technology (incl St. Olavs Hospital Trondheim University Hospital).

\section{Compliance with ethical standards}

Conflict of interest The authors declare that they have no conflict of interest.

Ethical approval All procedures performed in studies involving human participants were in accordance with the ethical standards of the Regional Committee for Medical and Health Research Ethics in Central Norway (REC ref. 2014/103-1) and with the 1964 Helsinki declaration and its later amendments or comparable ethical standards.

Informed consent Informed consent was obtained from all individual participants included in the study.

Open Access This article is licensed under a Creative Commons Attribution 4.0 International License, which permits use, sharing, adaptation, distribution and reproduction in any medium or format, as long as you give appropriate credit to the original author(s) and the source, provide a link to the Creative Commons licence, and indicate if changes were made. The images or other third party material in this article are included in the article's Creative Commons licence, unless indicated otherwise in a credit line to the material. If material is not included in the article's Creative Commons licence and your intended use is not permitted by statutory regulation or exceeds the permitted use, you will need to obtain permission directly from the copyright holder. To view a copy of this licence, visit http://creativecommons.org/licenses/by/4.0/.

\section{References}

1. Aaronson NK, Ahmedzai S, Bergman B, Bullinger M, Cull A, Duez NJ, Filiberti A, Flechtner H, Fleishman SB, de Haes JC et al (1993) The European Organization for Research and Treatment of Cancer QLQ-C30: a quality-of-life instrument for use in international clinical trials in oncology. J Natl Cancer Inst 85:365-376

2. Bloch O, Han SJ, Cha S, Sun MZ, Aghi MK, McDermott MW, Berger MS, Parsa AT (2012) Impact of extent of resection for recurrent glioblastoma on overall survival: clinical article. J Neurosurg 117:1032-1038. https://doi.org/10.3171/2012.9. Jns 12504

3. Brandes AA, Bartolotti M, Franceschi E (2013) Second surgery for recurrent glioblastoma: advantages and pitfalls. Expert Rev Anticancer Ther 13:583-587. https://doi.org/10.1586/era.13.32 
4. Charlson ME, Pompei P, Ales KL, MacKenzie CR (1987) A new method of classifying prognostic comorbidity in longitudinal studies: development and validation. J Chronic Dis 40:373-383

5. Cook CE (2008) Clinimetrics corner: the minimal clinically important change score (MCID): a necessary pretense. J Man Manip Ther 16:E82-E83. https://doi.org/10.1179/jmt.2008.16.4.82E

6. De Bonis P, Fiorentino A, Anile C, Balducci M, Pompucci A, Chiesa S, Sica G, Lama G, Maira G, Mangiola A (2013) The impact of repeated surgery and adjuvant therapy on survival for patients with recurrent glioblastoma. Clin Neurol Neurosurg 115:883-886. https://doi.org/10.1016/j.clineuro.2012.08.030

7. Dolan P (1997) Modeling valuations for EuroQol health states. Med Care 35:1095-1108

8. Giovagnoli AR, Silvani A, Colombo E, Boiardi A (2005) Facets and determinants of quality of life in patients with recurrent high grade glioma. J Neurol Neurosurg Psychiatry 76:562-568. https:// doi.org/10.1136/jnnp.2004.036186

9. Goldman DA, Hovinga K, Reiner AS, Esquenazi Y, Tabar V, Panageas KS (2018) The relationship between repeat resection and overall survival in patients with glioblastoma: a timedependent analysis. J Neurosurg 129:1231-1239. https://doi.org/ 10.3171/2017.6.Jns17393

10. Hervey-Jumper SL, Berger MS (2014) Reoperation for recurrent high-grade glioma: a current perspective of the literature. Neurosurgery 75:491-499; discussion 498-499. https://doi.org/10. 1227/neu.0000000000000486

11. Jakola AS, Gulati S, Weber C, Unsgard G, Solheim O (2011) Postoperative deterioration in health related quality of life as predictor for survival in patients with glioblastoma: a prospective study. PLoS One 6:e28592. https://doi.org/10.1371/journal.pone. 0028592

12. Jakola AS, Solheim O, Gulati S, Sagberg LM (2017) Is there a response shift in generic health-related quality of life 6 months after glioma surgery? Acta Neurochir 159:377-384. https://doi.org/10. 1007/s00701-016-3040-9

13. Kleihues P, Louis DN, Scheithauer BW, Rorke LB, Reifenberger G, Burger PC, Cavenee WK (2002) The WHO classification of tumors of the nervous system. J Neuropathol Exp Neurol 61:215225 discussion 226-219

14. Landriel Ibanez FA, Hem S, Ajler P, Vecchi E, Ciraolo C, Baccanelli M, Tramontano R, Knezevich F, Carrizo A (2011) A new classification of complications in neurosurgery. World Neurosurg 75:709-715; discussion 604-711. https://doi.org/10. 1016/j.wneu.2010.11.010

15. Lasocki A, Tsui A, Tacey MA, Drummond KJ, Field KM, Gaillard F (2015) MRI grading versus histology: predicting survival of World Health Organization grade II-IV astrocytomas. AJNR Am J Neuroradiol 36:77-83. https://doi.org/10.3174/ajnr.A4077

16. Louis DN, Ohgaki H, Wiestler OD, Cavenee WK, Burger PC, Jouvet A, Scheithauer BW, Kleihues P (2007) The 2007 WHO classification of tumours of the central nervous system. Acta Neuropathol 114:97-109. https://doi.org/10.1007/s00401-0070243-4

17. Lu VM, Jue TR, McDonald KL, Rovin RA (2018) The survival effect of repeat surgery at glioblastoma recurrence and its trend: a systematic review and meta-analysis. World Neurosurg 115:453459.e453. https://doi.org/10.1016/j.wneu.2018.04.016

18. McGirt MJ, Chaichana KL, Gathinji M, Attenello FJ, Than K, Olivi A, Weingart JD, Brem H, Quinones-Hinojosa AR (2009) Independent association of extent of resection with survival in patients with malignant brain astrocytoma. J Neurosurg 110:156-162. https://doi.org/10.3171/2008.4.17536

19. McHorney CA, Tarlov AR (1995) Individual-patient monitoring in clinical practice: are available health status surveys adequate? Qual Life Res 4:293-307
20. Molinari E, Mendoza TR, Gilbert MR (2018) Opportunities and challenges of incorporating clinical outcome assessments in brain tumor clinical trials. Neuro-Oncology Practice 6:81-92. https://doi. org/10.1093/nop/npy032

21. Nieder C, Grosu AL, Molls M (2000) A comparison of treatment results for recurrent malignant gliomas. Cancer Treat Rev 26:397409. https://doi.org/10.1053/ctrv.2000.0191

22. Nord E (1991) EuroQol: health-related quality of life measurement. Valuations of health states by the general public in Norway. Health Policy 18:25-36

23. Oppenlander ME, Wolf AB, Snyder LA, Bina R, Wilson JR, Coons SW, Ashby LS, Brachman D, Nakaji P, Porter RW, Smith KA, Spetzler RF, Sanai N (2014) An extent of resection threshold for recurrent glioblastoma and its risk for neurological morbidity. J Neurosurg 120:846-853. https://doi.org/10.3171/2013.12. Jns13184

24. Ostrom QT, Gittleman H, Fulop J, Liu M, Blanda R, Kromer C, Wolinsky Y, Kruchko C, Barnholtz-Sloan JS (2015) CBTRUS statistical report: primary brain and central nervous system tumors diagnosed in the United States in 2008-2012. Neuro-Oncology 17(Suppl 4):iv1-iv62. https://doi.org/10.1093/neuonc/nov189

25. Perrini P, Gambacciani C, Weiss A, Pasqualetti F, Delishaj D, Paiar F, Morganti R, Vannozzi R, Lutzemberger L (2017) Survival outcomes following repeat surgery for recurrent glioblastoma: a singlecenter retrospective analysis. J Neuro-Oncol 131:585-591. https:// doi.org/10.1007/s11060-016-2330-7

26. Pinsker M, Lumenta C (2001) Experiences with reoperation on recurrent glioblastoma multiforme. Zentralbl Neurochir 62:43-47. https://doi.org/10.1055/s-2002-19477

27. Prabhu VC, Barton KP, Walsh S, Borys E, Melian E (2017) Recurrent malignant gliomas: treatment options and their effect on patient's quality of life. World Neurosurg 103:906-910. https://doi.org/10.1016/j.wneu.2017.03.076

28. Quick J, Gessler F, Dutzmann S, Hattingen E, Harter PN, Weise LM, Franz K, Seifert V, Senft C (2014) Benefit of tumor resection for recurrent glioblastoma. J Neuro-Oncol 117:365-372. https:// doi.org/10.1007/s11060-014-1397-2

29. Ringel F, Pape H, Sabel M, Krex D, Bock HC, Misch M, Weyerbrock A, Westermaier T, Senft C, Schucht P, Meyer B, Simon M (2016) Clinical benefit from resection of recurrent glioblastomas: results of a multicenter study including 503 patients with recurrent glioblastomas undergoing surgical resection. Neuro-Oncology 18:96-104. https://doi.org/10.1093/neuonc/ nov145

30. Sagberg LM, Jakola AS, Solheim O (2014) Quality of life assessed with EQ-5D in patients undergoing glioma surgery: what is the responsiveness and minimal clinically important difference? Qual Life Res 23:1427-1434. https://doi.org/10. 1007/s11136-013-0593-4

31. Sawaya R, Hammoud M, Schoppa D, Hess KR, Wu SZ, Shi WM, Wildrick DM (1998) Neurosurgical outcomes in a modern series of 400 craniotomies for treatment of parenchymal tumors. Neurosurgery 42:1044-1055 discussion 1055-1046

32. Stark AM, Hedderich J, Held-Feindt J, Mehdorn HM (2007) Glioblastoma-the consequences of advanced patient age on treatment and survival. Neurosurg Rev 30:56-61; discussion 61-52. https://doi.org/10.1007/s10143-006-0051-7

33. Stockelmaier L, Renovanz M, Konig J, Nickel K, Hickmann AK, Mayer-Steinacker R, Nadji-Ohl M, Ganslandt O, Bullinger L, Wirtz CR, Coburger J (2017) Therapy for recurrent high-grade gliomas: results of a prospective multicenter study on health-related quality of life. World Neurosurg 102:383-399. https://doi.org/10.1016/j. wneu.2017.02.061

34. Stupp R, Mason WP, van den Bent MJ, Weller M, Fisher B, Taphoorn MJ, Belanger K, Brandes AA, Marosi C, Bogdahn U, Curschmann J, Janzer RC, Ludwin SK, Gorlia T, Allgeier A, 
Lacombe D, Cairncross JG, Eisenhauer E, Mirimanoff RO (2005) Radiotherapy plus concomitant and adjuvant temozolomide for glioblastoma. N Engl J Med 352:987-996. https://doi.org/10. 1056/NEJMoa043330

35. Suchorska B, Weller M, Tabatabai G, Senft C, Hau P, Sabel MC, Herrlinger U, Ketter R, Schlegel U, Marosi C, Reifenberger G, Wick W, Tonn JC, Wirsching HG (2016) Complete resection of contrast-enhancing tumor volume is associated with improved survival in recurrent glioblastoma-results from the DIRECTOR trial. Neuro-Oncology 18:549-556. https://doi.org/10.1093/neuonc/ nov326

36. Sughrue ME, Sheean T, Bonney PA, Maurer AJ, Teo C (2015) Aggressive repeat surgery for focally recurrent primary glioblastoma: outcomes and theoretical framework. Neurosurg Focus 38:E11. https://doi.org/10.3171/2014.12.Focus14726

37. Terasaki M, Ogo E, Fukushima S, Sakata K, Miyagi N, Abe T, Shigemori M (2007) Impact of combination therapy with repeat surgery and temozolomide for recurrent or progressive glioblastoma multiforme: a prospective trial. Surg Neurol 68:250 254. https://doi.org/10.1016/j.surneu.2006.11.042

38. The EuroQol Group (1990) EuroQol-a new facility for the measurement of health-related quality of life. Health Policy 16:199-208

39. Yong RL, Wu T, Mihatov N, Shen MJ, Brown MA, Zaghloul KA, Park GE, Park JK (2014) Residual tumor volume and patient survival following reoperation for recurrent glioblastoma. J Neurosurg 121:802-809. https://doi.org/10.3171/2014.6.Jns132038

40. Zhao YH, Wang ZF, Pan ZY, Peus D, Delgado-Fernandez J, Pallud J, Li ZQ (2019) A meta-analysis of survival outcomes following reoperation in recurrent glioblastoma: time to consider the timing of reoperation. Front Neurol 10:286. https://doi.org/10.3389/fneur. 2019.00286

Publisher's note Springer Nature remains neutral with regard to jurisdictional claims in published maps and institutional affiliations. 